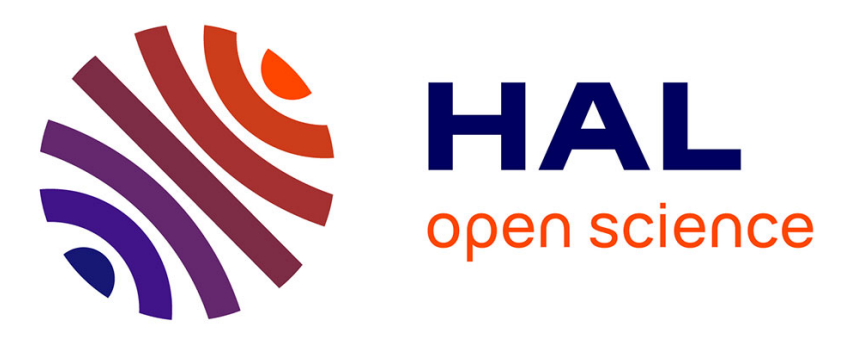

\title{
High-Overtone Bulk Acoustic Wave Resonator on Galliumnitride
}

M. Loschonsky, D. Eisele, J. Masson, M. Wieneke, S. Alzuaga, A. Dadgar, S. Ballandras, A. Krost, L. Reindl

\section{- To cite this version:}

M. Loschonsky, D. Eisele, J. Masson, M. Wieneke, S. Alzuaga, et al.. High-Overtone Bulk Acoustic Wave Resonator on Galliumnitride. Joint Meeting of the 23rd European Frequency and Time Forum/IEEE International Frequency Control Symposium, Apr 2009, Besançon, France. pp.309-315, 10.1109/FREQ.2009.5168192 . hal-00533725

\section{HAL Id: hal-00533725 \\ https://hal.science/hal-00533725}

Submitted on 11 May 2021

HAL is a multi-disciplinary open access archive for the deposit and dissemination of scientific research documents, whether they are published or not. The documents may come from teaching and research institutions in France or abroad, or from public or private research centers.
L'archive ouverte pluridisciplinaire HAL, est destinée au dépôt et à la diffusion de documents scientifiques de niveau recherche, publiés ou non, émanant des établissements d'enseignement et de recherche français ou étrangers, des laboratoires publics ou privés. 


\title{
High-Overtone Bulk Acoustic Wave Resonator on Galliumnitride
}

\author{
Marc Loschonsky ${ }^{1}$, David Eisele ${ }^{1}$, Jeremy Masson $^{1}$, Matthias Wieneke ${ }^{2}$, Sebastien Alzuaga ${ }^{3}$, Armin Dadgar ${ }^{2}$, \\ Sylvain Ballandras ${ }^{3}$, Alois Krost ${ }^{2}$, Leonhard Reindl ${ }^{1}$ \\ ${ }^{1}$ IMTEK - Department of Microsystems Engineering, Albert-Ludwigs-Universität Freiburg, Laboratory for Electrical \\ Instrumentation, Georges-Koehler-Allee 103, 79110 Freiburg, Germany, \\ Corresponding authors contact: marc.loschonsky@imtek.de
}

${ }^{2}$ Institut für Experimentelle Physik, Fakultät für Naturwissenschaften, Otto-von-Guericke-Universität Magdeburg, Universitätsplatz 2, 39106 Magdeburg, Germany

${ }^{3}$ cnrs-UFC-ENSMM-UTBM, Département Temps-Fréquence, 26 Chemin de l'Epitaphe, 25030 Besancon, France

\begin{abstract}
In our previous research we already demonstrated micro acoustic devices, such as membrane based thin film bulk acoustic shear wave resonators and surface acoustic shear wave resonators, based on Metal-Organic-Vapour-PhaseEpitaxial (MOVPE) grown highly oriented a-plane piezoelectric material. Although MOVPE is a well established process for compound semiconductor layer growth especially of III-V semiconductors as InP, GaAs, and the nitrides GaN or AIN as also design and simulation of micro acoustic devices is nowadays a well established knowledge, the linkage between both is quite a technological challenge. Using an adapted MOVPE growth process for a-plane GaN on r-plane sapphire with a process linked improved surface quality; the challenge to build up high-overtone bulk acoustic wave resonators (HBAR) with a shear polarization of the acoustic wave was risen within this research. Different designs of MEMS-based prototypes of HBARs were processed on a-plane GaN after intensive simulations, their acoustic electrical behaviour analyzed and the temperature coefficient of frequency determined.
\end{abstract}

\section{INTRODUCTION}

High-overtone bulk acoustic wave resonators (HBARs) devices are based on the effect of an almost total wave reflection at the substrates bottom interface to air at the backside of the substrate. The sputtered piezoelectric resonator layer, such as $\mathrm{AlN}$ or $\mathrm{ZnO}$, is in between two metal layers, which are functioning as electrodes. Now, instead of using a sputter deposition process for the piezoelectric resonator layer on top of a thin film metal layer, a MOVPE process was used to guarantee highly and homogenous oriented a-plane GaN. Therefore, MOVPE growth directly on top of the r-plane sapphire substrate is required. Crystal growth of group-III-nitride layers is a currently well established process for light emitting devices and high-power transistors and recently high-frequency application as surface or bulk acoustic wave devices [1],[2],[3]. These works are mainly focused on c-plane oriented material like c-plane AIN or $\mathrm{GaN}$ most on silicone or some on c-plane sapphire substrates. Typical growth methods are molecular beam epitaxy (MBE) and MOVPE, the latter widely used in mass production. The layers are usually c-axis oriented when grown on the surfaces of sapphire (0001), silicon carbide $(11 \overline{2} 0)$ or silicon (111). By using r-plane sapphire or a-plane $\mathrm{SiC}$, it is possible to switch the growth orientation and obtain a-plane GaN or AlN layers [4]. This is presently an active research topic with the focus on improving the efficiency of green LEDs. In LEDs grown with c-axis orientation, the piezoelectric polarization fields along the growth axis lead to a reduction in quantum efficiency, especially for longer wavelength LEDs.

The benefit of epitaxial growth as MOVPE compared to most other deposition techniques are a high crystalline quality, a low defect density, and usually a very good morphology. This also leads to improved acoustic properties, especially since the layer is a close to a single crystalline film, having only few boundaries, which originate in the initial island type growth. MOVPE grown GaN, therefore, seems to be an interesting candidate. Also, the MOVPE process was modified to enabling the growth of a conductive crystal layer [5] serving as integrated buried electrode.

\section{MOVPE GROWTH OF GALLIUM NITRIDE FOR THE DIFFERENT FUNCTIONAL LAYERS OF AN HBAR}

To accomplish a-plane oriented GaN layers MOVPE growth was performed on epi-polished r-plane (10 $\overline{1} 2)$ sapphire substrates of $330 \mu \mathrm{m}$ thickness. The MOVPE system is an AIXTRON AIX 200-4 RF/S with optical ports for in-situ measurement of curvature and layer thickness. To enable epitaxial growth, at first a $\sim 20 \mathrm{~nm} \mathrm{GaN}$ seeding layer 
was grown at $\sim 700^{\circ} \mathrm{C}$, followed by a $100 \mathrm{~nm}$ GaN:Si layer with a Si-concentration of more than 2E18 acting as shallow donors. This conductive crystalline layer served as a buried electrode. In the following, a pure $2 \mu \mathrm{m}$ $\mathrm{GaN}$ layer was grown at $200 \mathrm{mbar}$ and $1045^{\circ} \mathrm{C}$. Both process steps were using standard high purity precursors as trimethyl-gallium and ammonia with high purity carrier gases $\mathrm{H}_{2}$ and $\mathrm{N}_{2}$. Finally, a second GaN:Si layer was grown with the same concentration of $\mathrm{Si}$ as the first conductive layer, serving as a top electrode for the HBAR (Figure 1).

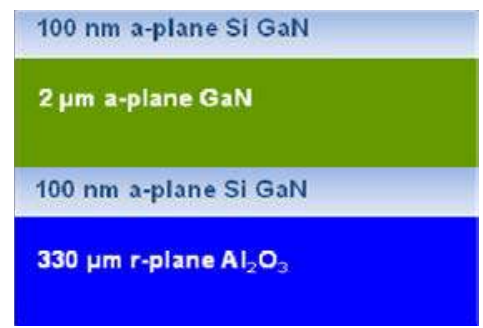

Figure 1 Schematic view of layer stack of an HBAR with the corresponding thicknesses and the material composition. Not shown is the thin GaN crystal seed layer which is grown at first atop the r-plane sapphire.

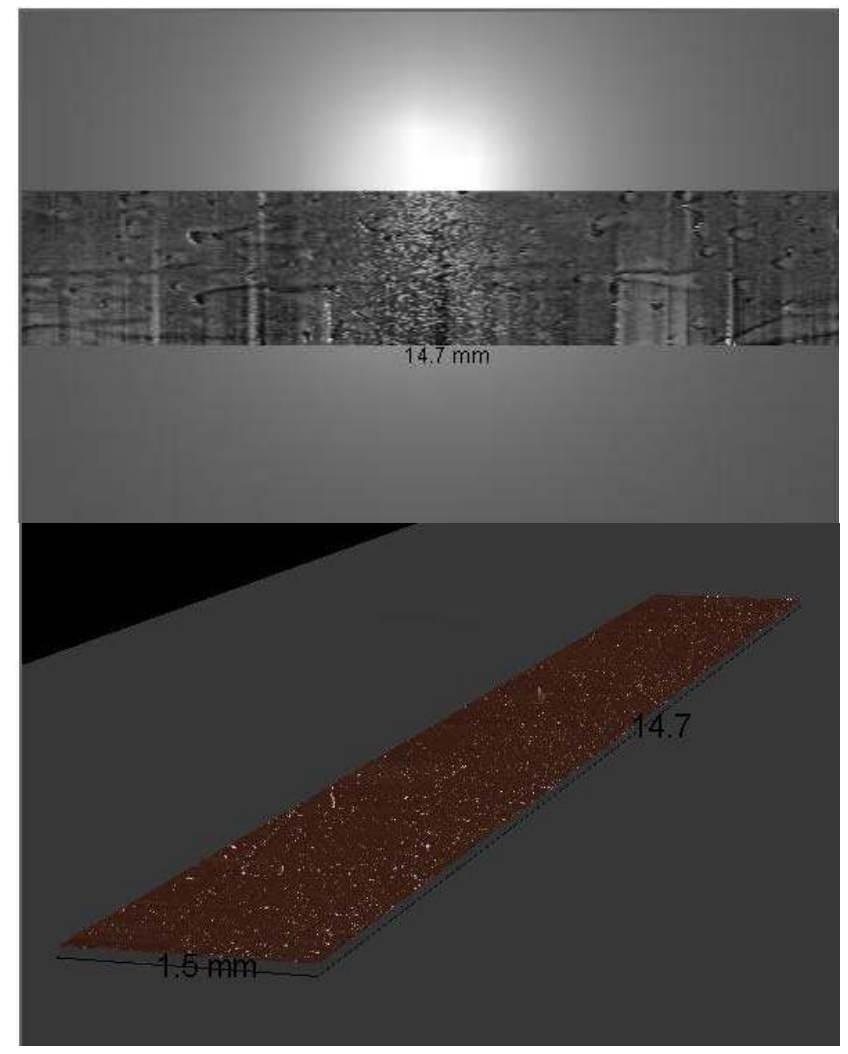

Figure 2 Two 3D surface profilometry scans of a GaN:Si surface which shows both the surface quality of a $1.5 \times 14.7 \mathrm{~mm}^{2}$ scan field. The perspective of the first one is indicated by the perspective light, the second is an obvious perspective and shows from brown to white coloured minima and maxima. The roughneess value were found to be pretty good at $\mathrm{R}_{\mathrm{a}}=42.62 \mathrm{~nm}, \mathrm{R}_{\mathrm{q}}=72.92 \mathrm{~nm}$ and $\mathrm{R}_{\mathrm{t}}=4.54 \mu \mathrm{m}$.

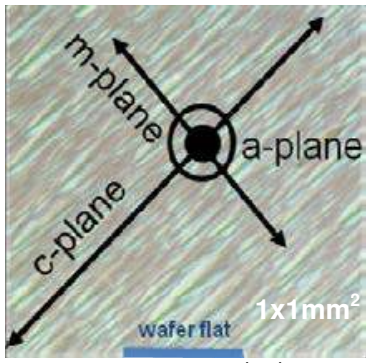

Previous GaN $(0|90| 0)$

$\mathrm{R}_{\mathrm{a}}(\mathrm{m})=4441 \AA, \mathrm{R}_{\mathrm{a}}(\mathrm{c})=971 \AA$

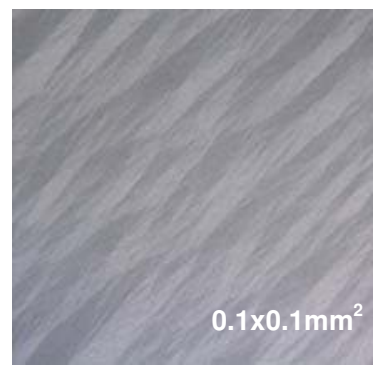

Improved $\mathrm{GaN}(0|90| 0)$

$\mathrm{Ra}(\mathrm{m})=3606 \AA$, $\mathrm{R} \mathrm{a}(\mathrm{c})=680 \AA$
Figure 3 Sureface morphology and roughness of unpolished, textured a-plane GaN (light microscope photos) of previous [6] and improved process [7].

The influence of the added Si-atoms for achieving a conductive layer degraded the surface morphology of the resulting grown crystal surface. The low thickness of $100 \mathrm{~nm}$ of the GaN:Si top layer did not allow any chemical or mechanical assisted polishing process after growth, therefore the MOVPE growth process itself had to be further improved to be competitive with already achieved previous results, refer to Figure 3, for providing a comparable surface quality as shown in Figure 2

\section{DESIGN AND PROCESSING OF A-PLANE GAN HBARS}

A rectangular design was chosen for the HBARs where the resonator and electrode size was varied from $200 \mu \mathrm{m}$ up to $400 \mu \mathrm{m}$ in steps of $25 \mu \mathrm{m}$ on each side. After the initial MOVPE crystal growth processes, a lithography step followed. To etch the resonators and the electrodes a chemical assisted ion beam etching process (CAIBE) was used. As contact pads to the GaN:Si electrode layers a $100 \mathrm{~nm}$ thick gold layer with a chromium adhesion layer was deposited by physical vapour deposition (PVD) process, followed by a classical wet etching of the contact pads.

Two different process designs where realised to demonstrate the feasibility of conductive GaN:Si layers serving as electrodes, as shown in Figure 4
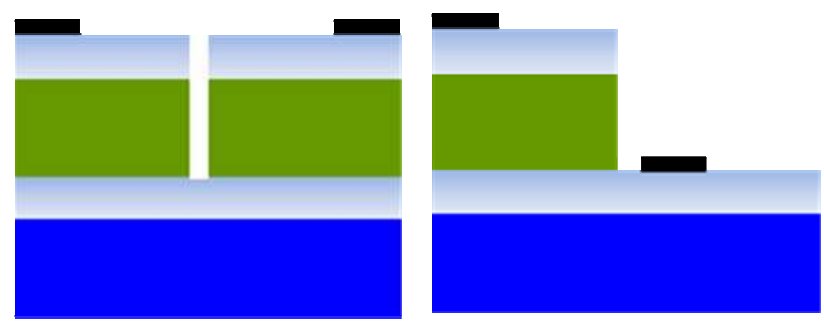

Figure 4 Two different process designs for demonstration. left side: two resonators in series connected with an integrated GaN:Si conductive layer and two $\mathrm{Cr} / \mathrm{Au}$ contact pads,

right side: one single resonator connected with a contact pad atop the resonator and atop the integrated $\mathrm{GaN}$ :Si conductive layer, serving as a bottom electrode. 


\section{SimUlation AND MEASUREMENT}

\section{A. Simulation of the HBAR devices}

The HBAR structure was simulated by a 2D-simulation software based on a scattering matrix method for multilayered media [8],[9], which itself based on the transfer matrix method from Fahmy and Adler [10]. Both a perfect reflecting and a non-reflecting backside of sapphire were simulated in a frequency range of $0 \mathrm{GHz}$ up to $4 \mathrm{GHz}$ and the static capacitance $\mathrm{C}_{0}=3.8 \mathrm{fF}$ was subtracted (Figure 5). Only the perfect reflecting backside condition enables the high overtones. By applying a FFT to the admittances, the respective impulse responses are obtained (Figure 6). The internal resonance in the piezoelectric layer splits into two shear and one longitudinal component wave at the bottom electrode-sapphire interface. The first three reflections in Figure 6 a) are the received first order reflections of these components, which are missing in Figure $6 \mathrm{~b}$ ), because of the non-reflective backside. The corresponding bulk wave velocities in the sapphire are about $10707 \mathrm{~m} / \mathrm{s}$ (fast shear), $6871 \mathrm{~m} / \mathrm{s}$ (slow shear) and $5742 \mathrm{~m} / \mathrm{s}$ (longitudinal).

\section{B. Measurements of the HBAR devices}

RF measurements and analysis were performed of the fabricated HBAR devices (Figure 7). The expected high overtones were missing and only a conventional resonance with a low quality factor $Q$ of about 5 was found. The analysis of the impulse response show that the reflections almost totally disappeared. Examination of the internal resonance of the piezoelectric layer (Figure 8) indicates a slightly higher reflection between bottom electrode and sapphire than indicated by simulation.

Additional simulations of the slowness curves of r-plane sapphire were made (Figure 9) and the directions of the power flow of the three bulk waves were investigated:

- Fast shear wave: $\quad x$-tilt of $-13^{\circ}, y$-tilt of $-5^{\circ}$

- Slow shear wave: $x$-tilt of $-6^{\circ}, y$-tilt of $+7^{\circ}$

- Longitudinal wave: $x$-tilt of $-4^{\circ}$, y-tilt of $-17^{\circ}$

One reasonable explanation for the missing of the high overtones and the conventional resonance with a $\mathrm{Q}$ of about 5 might be the crystal orientation of the r-plane sapphire itself. The r-plane orientation might deflect the acoustical wave in this way that reflections are strongly prevented. In addition, scattering effects at the interface of the GaN:Si and $\mathrm{GaN}$ crystal seed layer on the sapphire are possible and will be further investigated.
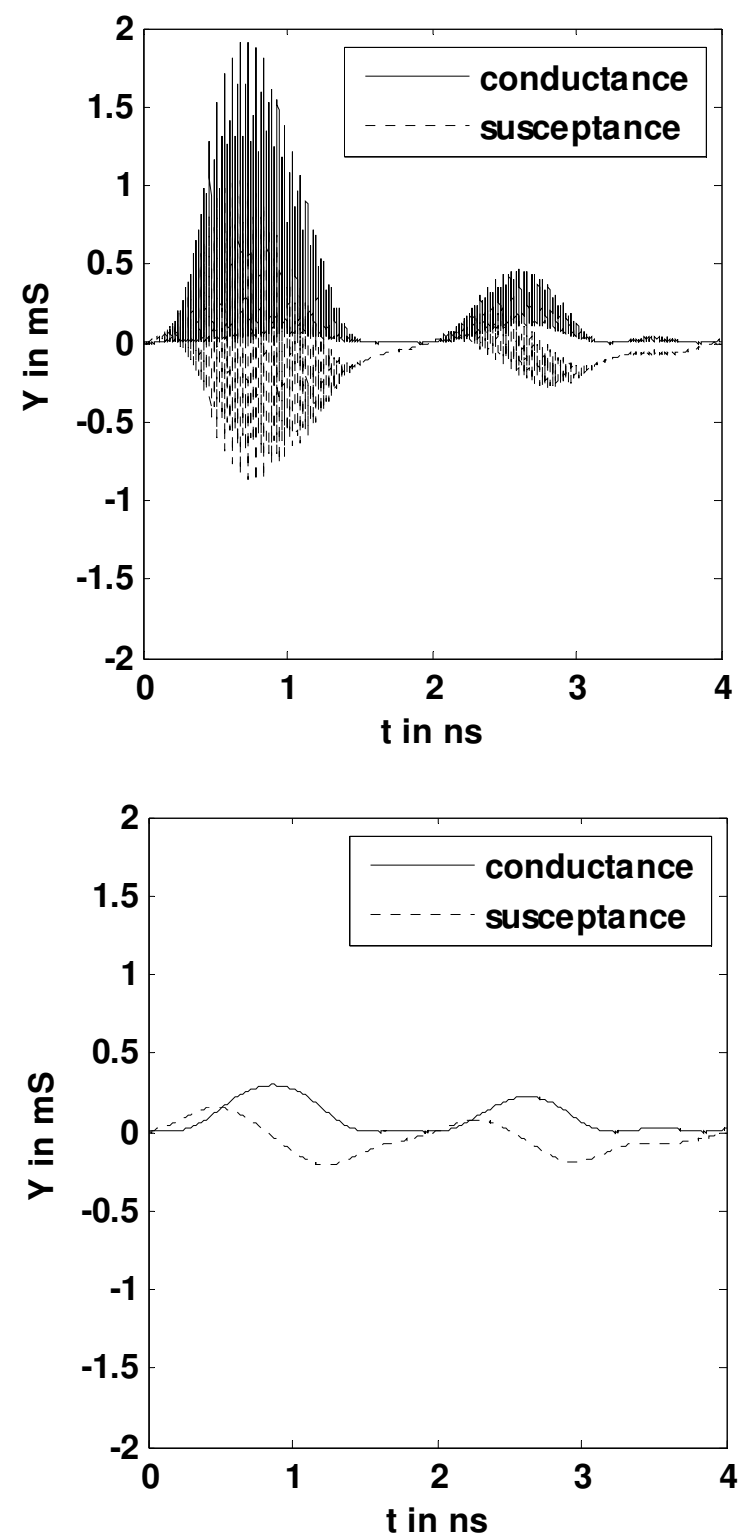

Figure 5 2D-Simulated HBAR admittances, a) perfect reflecting b) nonreflecting backside of sapphire. The imaginary part of the static capacitance $\mathrm{C}_{0}=3.8 \mathrm{fF}$ was subtracted. 

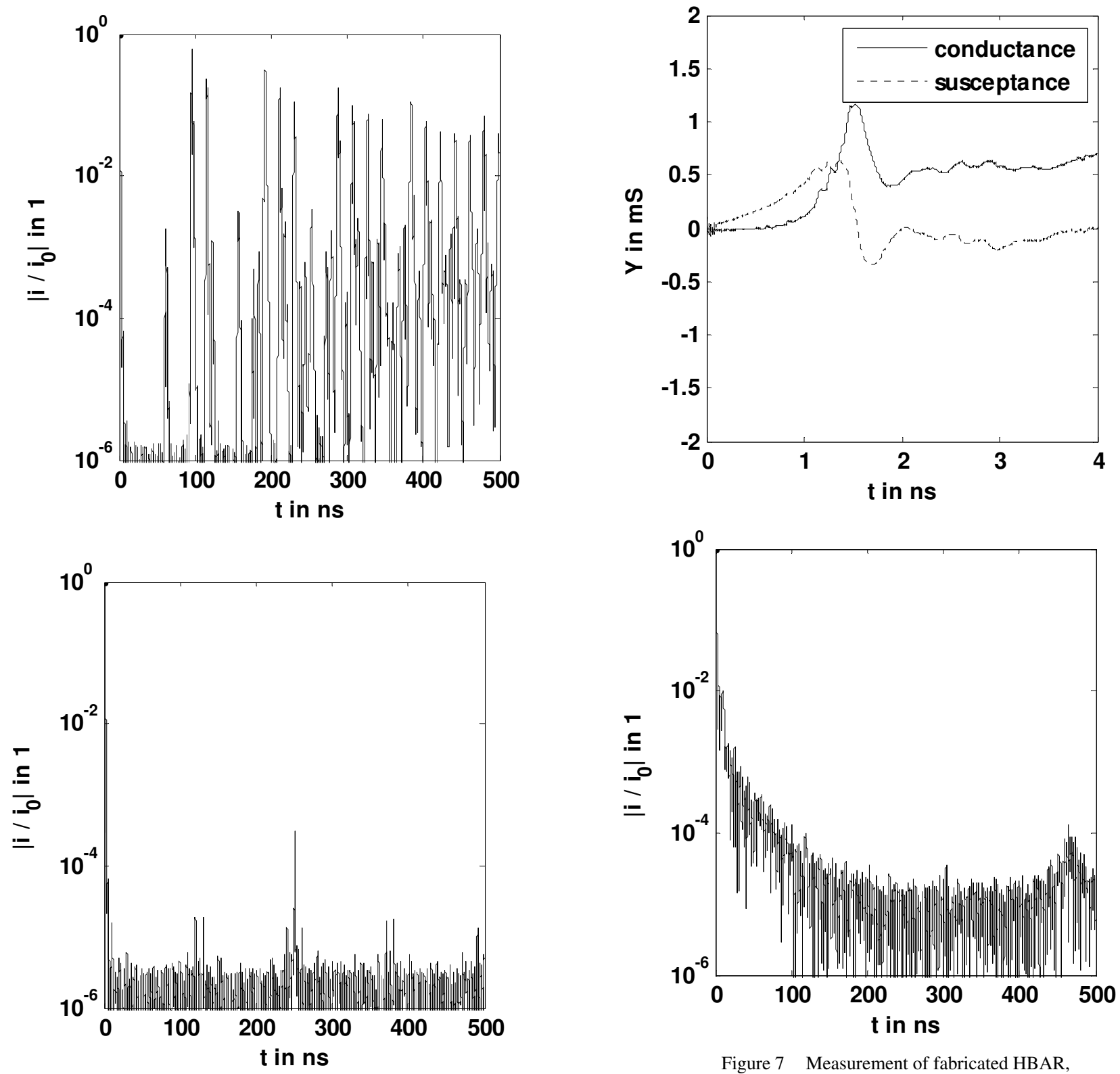

Figure 7 Measurement of fabricated HBAR, a) admittance b) normalized impulse response.

Figure 6 2D-Simulated HBAR impulse responses normalized, a) perfect reflecting $b$ ) non-reflecting backside of sapphire. 

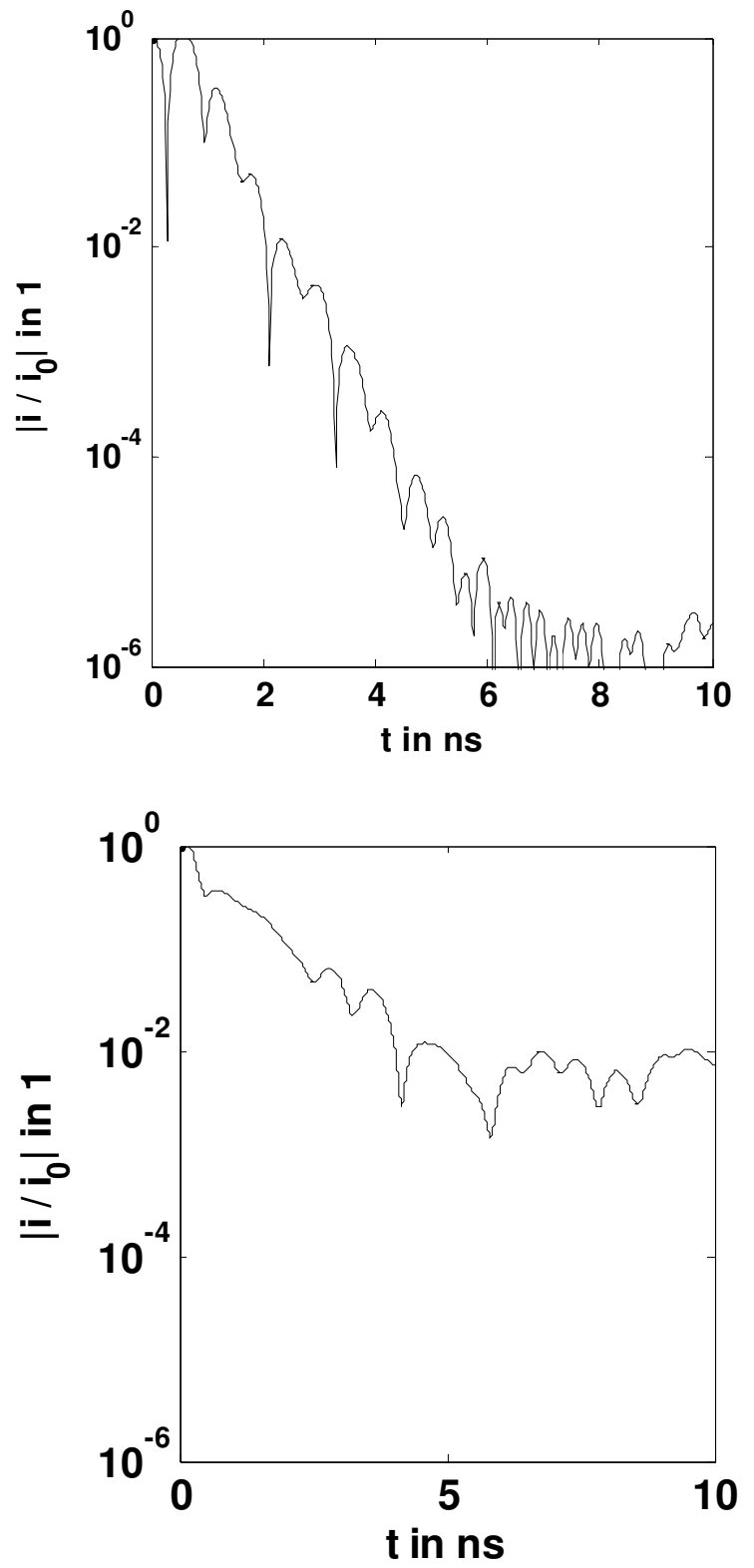

Figure 8 Comparison of normalized impulse responses of a) simulated b) measured HBAR.

Only the first nanoseconds with the internal resonance of the piezoelectric layer is shown.
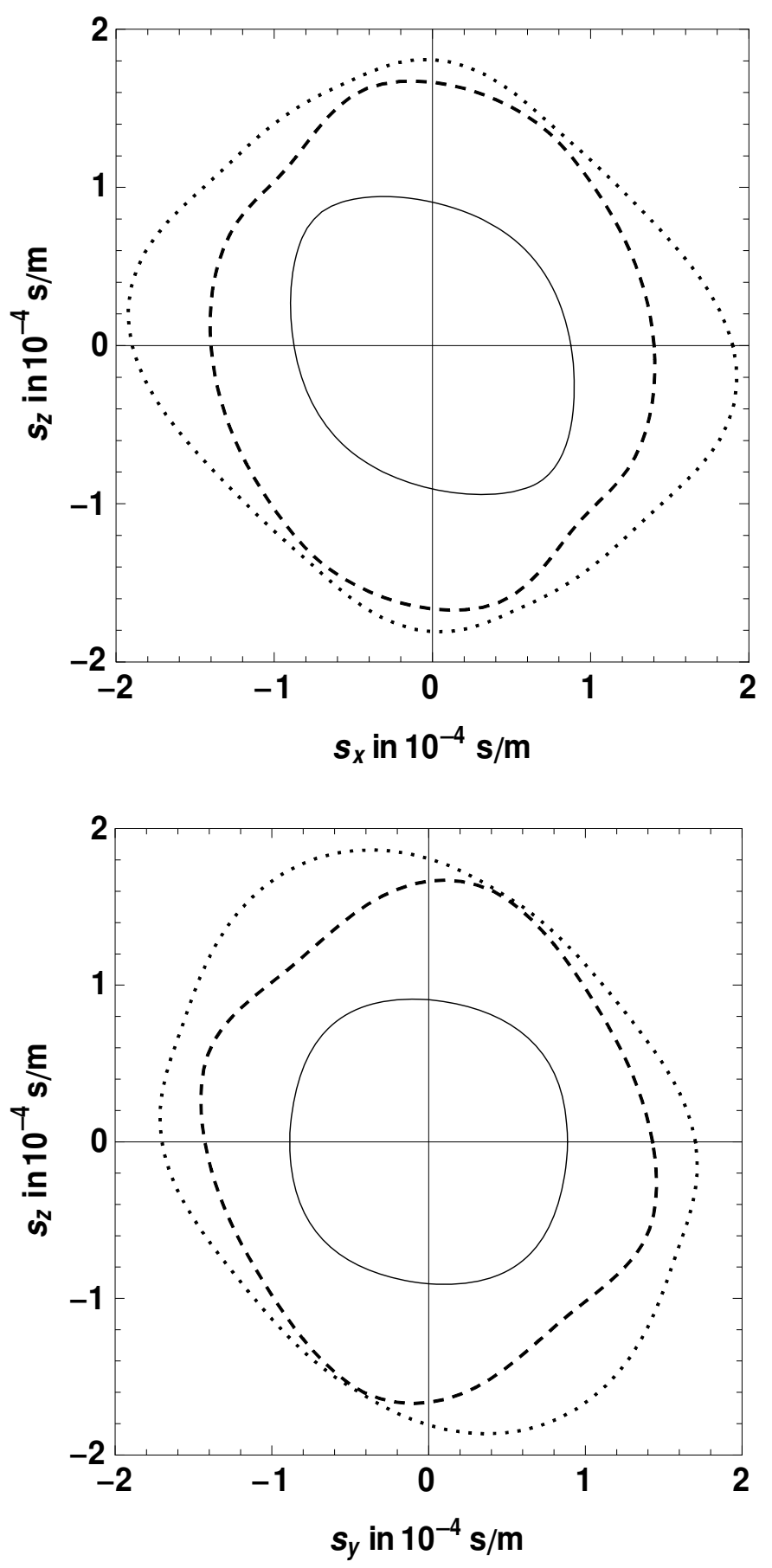

Figure 9 Slowness curves of r-plane sapphire used as substrate: a) XZ-plane b) YZ-plane.

Solid line: fast shear wave, dashed line: slow shear wave, dotted line: longitudinal wave.

Strong anisotropy of the material cause tilted Poynting vectors. 


\section{Temperature coefficient of resonance frequency}

The temperature coefficient of frequency for different HBARs were measured with a Digit Concept Thermal Chuck on a Cascade Summit probe station in a temperature range from room temperature up to $200^{\circ} \mathrm{C}$. For frequency analysis, the first resonance of each HBAR was measured with a ZVA-24 vector network analyzer from Rhode\&Schwarz.

As shown in the different graphs of Figure 10 all resonators exhibit a negative temperature coefficient of frequency in a range of -13 to $-17 \mathrm{ppm} / \mathrm{K}$. The temperature coefficient of frequency seems to vary periodical with rising temperature. The elasticity of $\mathrm{GaN}$ with built in $\mathrm{Si}$ atoms may influence its elastically characteristics.
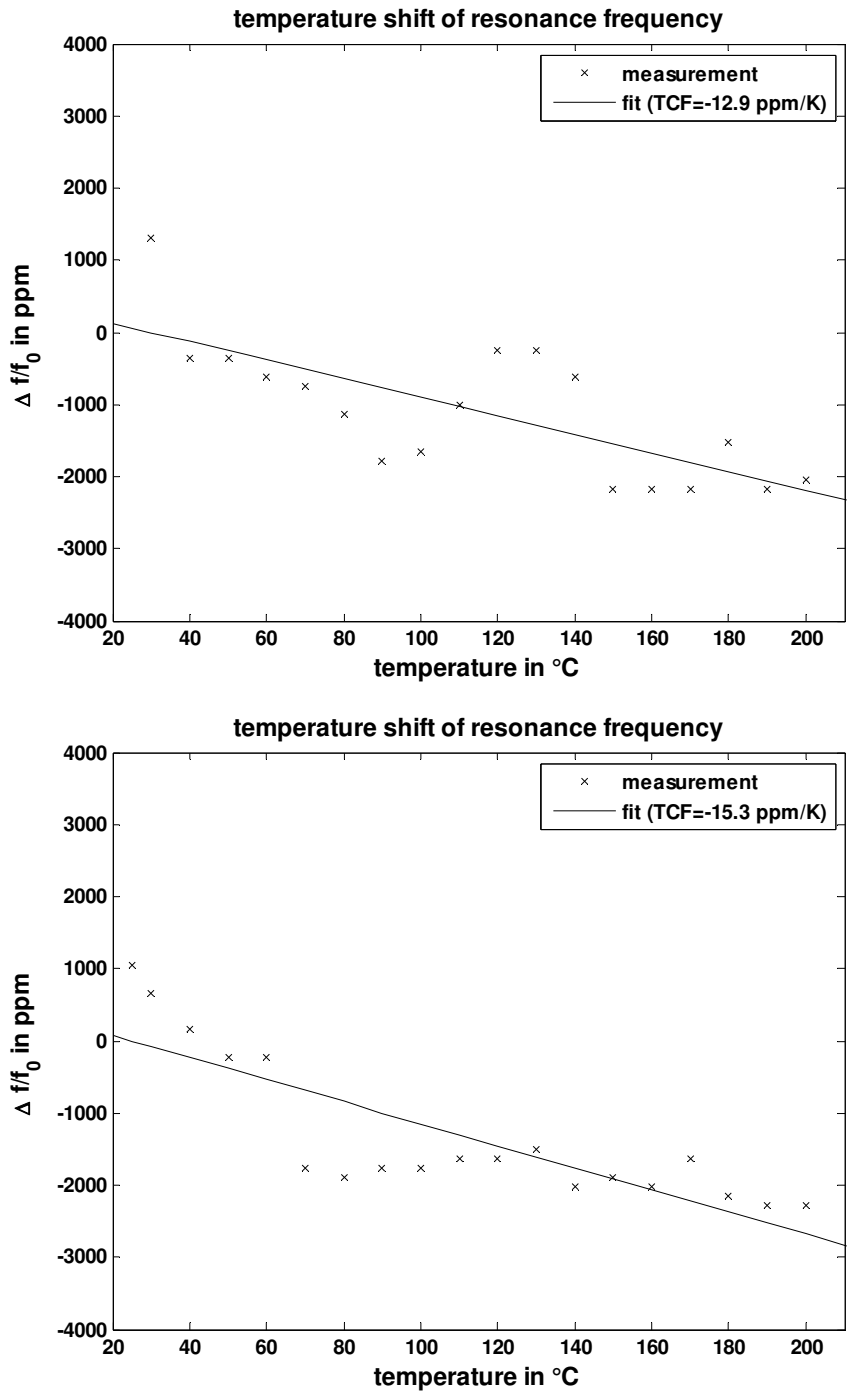
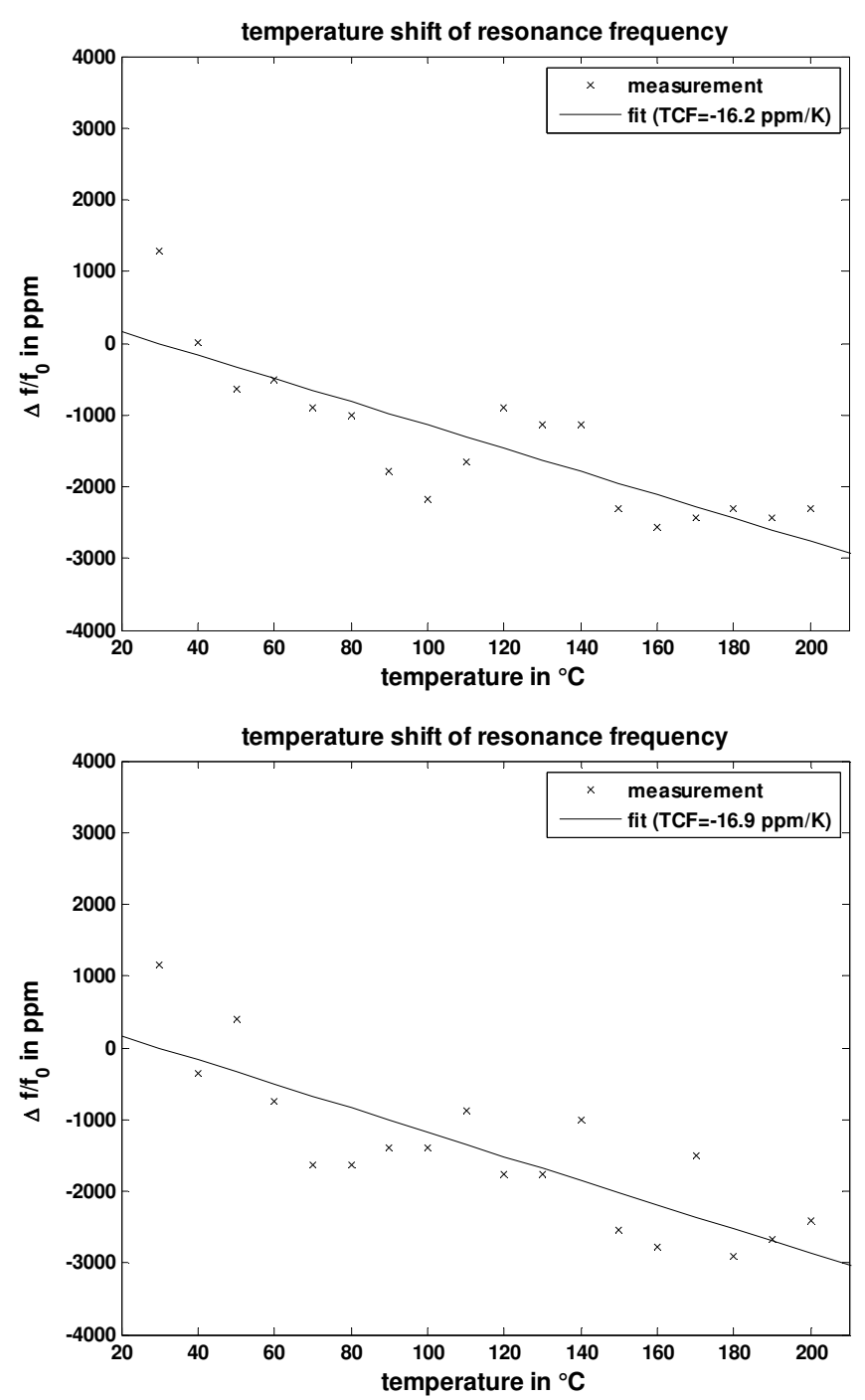

Figure 10 Temperature coefficient of resonance frequency at $25^{\circ} \mathrm{C}$ of different HBAR prototypes.

\section{CONCLUSION}

High-overtone bulk acoustic resonators acoustic wave devices based on MOVPE grown crystalline gallium nitride thin films with a-plane orientation gallium nitride were successfully fabricated and characterized, but there behavior totally deferred from what would have been expected. For a first understanding, additional simulations were and will be further achieved, considering the influence of r-plane sapphire's crystal orientation. In addition, the influence of the built-in Si atoms within the GaN crystal lattice to enable $\mathrm{GaN}$ becoming a conductive material will be analyzed in further research. This conductive crystalline layer could also affect the temperature coefficient of frequency with rising temperature due to its completely changed elastic behavior. Further work will be focused in extracting and measuring material parameters of gallium nitride thin films for 
matching simulation with measurements and an expansion of the focus of our work on other MOVPE grown a-plane oriented piezoelectric III-V compound semiconductors like aluminum nitride.

\section{ACKNOWLEDGMENT}

R. B. G. thanks Michael Wandt, Armin Baur, Michael Reichel, Nico Lehmann, Philip Katus, Christopher W. Hodges and Maya Malkani for fruitful discussions along the time for this work.

\section{REFERENCES}

[1] M. N. Yoder, "Gallium nitride past, present, and future," High Speed Semiconductor Devices and Circuits, 1997. Proceedings., 1997 IEEE/Cornell Conference on Advanced Concepts in, 1997, pp. 3-12.

[2] U. K. Misra, Shen Likun, T. E. Kazior, Wu Yi-Feng, "GaN-Based RF Power Devices and Amplifiers," Proceedings of the IEEE, vol. 96, no.2, 2008, pp. 287-305.

[3] A. Müller, D. Neculoiu, D. Vasilache, D. Dascalu, G. Konstantinidis, A. Kosopoulos, A. Adikimenakis, A. Georgakilas, K. Mutamba, C. Sydlo, H.L. Hartnagel, A. Dadgar, "GaN micromachined FBAR structures for microwave applications," Superlattices and Microstructures, vol. 40, no. 4-6, 2006, pp. 426-431.

[4] T. Lei, K. F. Ludwig Jr., T. D. Moustakas, "Heteroepitaxy, polymorphism, and faulting in GaN thin films on silicon and sapphire substrates," J. Appl. Phys., vol. 74, 1993, pp. 4430.

[5] K. Nishimura, N. Shigekawa, H. Yokoyama, K. Hohkawa, "SAW characteristics of $\mathrm{GaN}$ with $\mathrm{n}^{+}-\mathrm{GaN}$ IDTs," Electronics Letters, vol.42, no.1, 5 Jan. 2006, pp. 62-63.
[6] M. Loschonsky, L. Reindl, A. Dadgar, M. Wieneke, J. Blasing, A. Krost, "a-plane GaN Shear Wave Thin Film Resonator," Frequency Control Symposium, 2007 Joint with the 21st European Frequency and Time Forum. IEEE International., May 29 -June 1 2007, pp.494498.

[7] M. Loschonsky, D. Eisele, A. Dadgar, A. Krost, S. Ballandras, L. Reindl, "Investigations of a-plane and c-plane GaN-based synchronous surface acoustic wave resonators," Frequency Control Symposium, 2008 IEEE International , 19-21 May 2008, pp.320-325.

[8] A. Reinhardt, T. Pastureaud, S. Ballandras, and V. Laude, "Scattering matrix method for modelling acoustic waves in piezoelectric, fluid, and metallic multilayers," J. of Applied Physics, vol. 94, no. 10, 2003, pp. 2544-2546.

[9] A. Reinhardt, V. Laude, Th. Pastureaud and S. Ballandras, "Numerical simulation and comparison of membrane and solidly mounted FBAR's", Proceedings of the IEEE Ultrasonics Symposium, 2002, pp. 497-500.

[10] A. Fahmy, E. Adler, "Propagation of acoustic surface waves in multilayers: A matrix description", Journal of Applied Physics Letter, vol. 22, 1973, pp. 495-497. 